\title{
Hypertension control is needed in elderly marathon runners!
}

\author{
Arnoud van der Laarse $\cdot$ Ernst E. van der Wall
}

Received: 11 August 2008/Accepted: 11 August 2008/Published online: 2 September 2008

(C) The Author(s) 2008. This article is published with open access at Springerlink.com

The performance of sporting activities like cycling and running is a life style factor that improves health and increases the duration of healthy life [1, 2]. Heavy exercise, such as rowing, cycling, and marathon running at competitive levels, is considered to be healthy, although evidence of the opposite is published from time to time [3, 4]. It is known for quite some time that the hearts of extensive sport athletes develop left ventricular hypertrophy (LVH), known under the name of the "athlete's heart". This type of LVH is considered physiological [5-10]. Conditions like hypertensive heart disease lead to pathological LVH [11-15], as it is often associated with perivascular and interstitial fibrosis of left ventricular myocardium [16], diastolic heart failure [17, 18], arrhythmias [19, 20] and mortality [21].

Previous studies from our institution have already addressed the issue of physiological versus pathological LVH [5, 22, 23]. First of all we studied the accuracy of M-mode echocardiography and two different twodimensional echocardiographic approaches in the assessment of left ventricular mass and volumes in endurance-trained and strength-trained athletes, using cardiovascular magnetic resonance (CMR) imaging as reference standard [23]. It was shown that in general

A. van der Laarse · E. E. van der Wall ( $\square)$ Department of Cardiology, Leiden University Medical Center, P.O. Box 9600, Leiden, The Netherlands

e-mail: e.e.van_der_wall@lumc.nl practice the two-dimensional echocardiographic approach was the most accurate estimator of left ventricular mass and volumes in both controls and athletes. For research purposes, however, CMR remains the most accurate and reliable method to assess cardiac anatomy and function [24-27]. In a next study we addressed the question of whether training-induced left ventricular hypertrophy in athletes is a physiological rather than a pathophysiological phenomenon [28]. To that purpose we studied 21 elite cyclists and 12 healthy control subjects. Left ventricular mass, volume, and function were determined by CMR and myocardial high-energy phosphates were examined by 31P magnetic resonance spectroscopy. It was shown that LVH in cyclists was not associated with significant abnormalities of cardiac function or metabolism as assessed by CMR and spectroscopy. These observations suggested that training-induced left ventricular hypertrophy in cyclists is predominantly a physiological phenomenon. Finally in a meta-analysis paper, involving 59 studies and 1,451 athletes, i.e., endurance-trained athletes (long-distance runners), strength-trained athletes (weight lifters, power lifters, bodybuilders, wrestlers, and throwers), and athletes involved in combined forms of dynamic and static training (cyclists and rowers), we confirmed the hypothesis of divergent cardiac adaptations in dynamic and static sports [5]. Overall, the athlete's heart demonstrated normal systolic and diastolic cardiac functions. However, our meta-analysis concerned relatively young athletes between 18 and 40 years. 
Whether individuals older than 50 years engaged in exceptionally extensive sports have LVH and how this LVH relates to their cardiovascular risk factors is addressed by Nassenstein and colleagues in this issue of the International Journal of Cardiovascular Imaging [29]. They investigated 105 clinically healthy male marathon runners aged $\geq 50$ years and determined left ventricular muscle mass (LVMM) and diastolic and systolic left ventricular volumes (LVEDV and LVESV, respectively) by CMR imaging, diastolic and systolic blood pressure by an automatic blood pressure device, coronary artery calcifications (CAC) by electron beam computed tomography, plasma HDL and LDL cholesterol concentrations, smoking habits, and body mass index (BMI). Surprisingly, quite high percentages of individuals in this cohort demonstrated cardiovascular risk factors: $13 \%$ hypertension, 9.5\% hypercholesterolemia, and 33\% a $\mathrm{BMI} \geq 25 \mathrm{~kg} / \mathrm{m}^{2}$. In the whole cohort LVMM was positively correlated with systolic as well as diastolic blood pressure, thus the hypertensive runners are the ones with the highest LVMM. The authors also demonstrated that the CAC burden was significantly higher (by a factor $\approx 4$ ) in runners with $L V M M \geq 150 \mathrm{~g}$ than in those with $\mathrm{LVMM}<150 \mathrm{~g}$. From these results the authors drew the conclusion that in well-trained marathon runners (1) blood pressure contributes to LVH and (2) that LVMM should not be solely interpreted as a physiological adaptation to exercise. So, at least in a substantial percentage of this cohort of welltrained marathon runners aged $\geq 50$ years existing LVH is induced by physiological ánd pathological forces, maybe acting synergistically. As $\mathrm{LVMM} \geq 150 \mathrm{~g}$ is associated with extensive $\mathrm{CAC}$ and given the massive evidence of $\mathrm{LVH}$ being a risk factor [30, 31], hypertension in athletes, particularly older athletes, should be considered a reason to stop performing extensive endurance sports and start anti-hypertensive therapy. Consequently, elderly marathon runners should be carefully checked for the presence of hypertension.

Open Access This article is distributed under the terms of the Creative Commons Attribution Noncommercial License which permits any noncommercial use, distribution, and reproduction in any medium, provided the original author(s) and source are credited.

\section{References}

1. Haskell WL, Lee IM, Pate RR et al (2007) Physical activity and public health: updated recommendation for adults from the American College of Sports Medicine and the American Heart Association. Circulation 116:1081-1093

2. Nelson ME, Rejeski WJ, Blair SN et al (2007) Physical activity and public health in older adults: recommendation from the American College of Sports Medicine and the American Heart Association. Med Sci Sports Exerc 39:1435-1445

3. Wesslén L, Påhlson C, Lindquist O et al (1996) An increase in sudden unexpected cardiac deaths among young Swedish orienteers during 1979-1992. Eur Heart J 17:902-910

4. Keren G, Schoenfeld Y (1981) Sudden death and physical exertion. J Sports Cardiol 21:90-93

5. Pluim BM, Zwinderman AH, van der Laarse A, van der Wall EE (2001) The athlete's heart: a meta-analysis of cardiac structure and function. Circulation 101:336-344

6. Granger CB, Karimeddini MK, Smith VE et al (1985) Rapid ventricular filling in left ventricular hypertrophy. 1. Physiologic hypertrophy. J Am Coll Cardiol 5:862-868

7. Colan SD, Sanders SP, MacPherson D, Borow KM (1985) Left ventricular diastolic function in elite athletes with physiologic cardiac hypertrophy. J Am Coll Cardiol 6: 545-549

8. Colan SD, Sanders SP, Borow KM (1987) Physiologic hypertrophy: effects on left ventricular systolic mechanics in athletes. J Am Coll Cardiol 9:776-783

9. Maron BJ, Pellicia A, Spirito P (1995) Cardiac disease in young trained athletes: insights into methods for distinguishing athlete's heart from structural heart disease, with particular emphasis on hypertrophic cardiomyopathy. Circulation 5:1596-1601

10. Rapaport E (1982) Pathophysiological basis of left ventricular hypertrophy. Eur Heart J 3:29-33

11. Lorell B, Carabello B (2000) Left ventricular hypertrophy-pathogenesis, detection and prognosis. Circulation 102:470-479

12. Frohlich ED, Apstein C, Chobanian AV et al (1992) The heart in hypertension. N Engl J Med 327:998-1008

13. Koren MJ, Devereux RB, Casale PN, Savage DD, Laragh JH (1991) Relation of left ventricular mass and geometry to morbidity and mortality in uncomplicated essential hypertension. Ann Intern Med 114:345-352

14. Verdecchia P, Schillaci G, Boldrini F (1990) Risk stratification of left ventricular hypertrophy in systemic hypertension using noninvasive ambulatory blood pressure control. Am J Cardiol 66:583-590

15. Verdecchia P, Schillaci G, Borgioni C et al (1996) Prognostic value of left ventricular mass and geometry in systemic hypertension with left ventricular hypertrophy. Am J Cardiol 78:197-202

16. Moncrieff J, Lindsay MM, Dunn FG (2004) Hypertensive heart disease and fibrosis. Curr Opin Cardiol 9:326-331

17. Fouad FM, Slominski JM, Tarazi RC (1984) Left ventricular diastolic function in hypertension: relation to left ventricular mass and systolic function. J Am Coll Cardiol 3:1500-1506 
18. Lorell BH, Grossman W (1987) Cardiac hypertrophy: the consequences for diastole. J Am Coll Cardiol 9:1189-1193

19. McLenachan JM, Henderson E, Morris KI, Dargie HJ (1987) Ventricular arrhythmias in patients with hypertensive left ventricular hypertrophy. N Engl J Med 317: 787-792

20. Bikkina M, Larson MG, Levy D (1993) Asymptomatic ventricular arrhythmias and mortality risk in subjects with left ventricular hypertrophy. J Am Coll Cardiol 22: 1111-1116

21. Levy D, Garrison RJ, Savage DD, Kannel WB, Castelli WP (1990) Prognostic implications of echocardiographically determined left ventricular mass in the Framingham Heart Study. N Engl J Med 322:1561-1566

22. Pluim BM, Beyerbacht HP, Chin JC et al (1997) Comparison of echocardiography with magnetic resonance imaging in the assessment of the athlete's heart. Eur Heart J 18:1505-1513

23. Pluim BM, Chin JC, De Roos A et al (1996) Cardiac anatomy, function and metabolism in elite cyclists assessed by magnetic resonance imaging and spectroscopy. Eur Heart J 17:1271-1278

24. Posma JL, Blanksma PK, van der Wall EE, Hamer HP, Mooyaart EL, Lie KI (1996) Assessment of quantitative hypertrophy scores in hypertrophic cardiomyopathy: magnetic resonance imaging versus echocardiography. Am Heart J 132:1020-1027
25. van Rugge FP, Holman ER, van der Wall EE, de Roos A, van der Laarse A, Bruschke AV (1993) Quantitation of global and regional left ventricular function by cine magnetic resonance imaging during dobutamine stress in normal human subjects. Eur Heart J 14:456-463

26. Bavelaar-Croon CD, Kayser HW, van der Wall EE et al (2000) Left ventricular function: correlation of quantitative gated SPECT and MR imaging over a wide range of values. Radiology 217:572-575

27. Langerak SE, Vliegen HW, de Roos A et al (2002) Detection of vein graft disease using high-resolution magnetic resonance angiography. Circulation 105:328-333

28. Pluim BM, Lamb HJ, Kayser HW, Leujes F et al (1998) Functional and metabolic evaluation of the athlete's heart by magnetic resonance imaging and dobutamine stress magnetic resonance spectroscopy. Circulation 97:666-672

29. Nassenstein K, Breuckmann F, Lehmann N et al (2008) Left ventricular volumes and mass in marathon runners and their association with cardiovascular risk factors. Int $\mathbf{J}$ Cardiovasc Imaging. doi:10.1007/s10554-008-9337-x

30. Kannel WB (1996) Blood pressure as a cardiovascular risk factor. JAMA 275:1571-1576

31. van Lennep JE, Westerveld HT, van Lennep HW, Zwinderman AH, Erkelens DW, van der Wall EE (2000) Apolipoprotein concentrations during treatment and recurrent coronary artery disease events. Arterioscler Thromb Vasc Biol 20:2408-2413 